\title{
SYAIKH YUSUF QARDHAWI: GURU UMAT ISLAM PADA MASANYA
}

\author{
M. Khalilurrahman \\ Fakultas Syari'ah UIN Maliki Malang \\ Telepon: 085649675668 \\ Email: cholil_boyanes@yahoo.co.id
}

\section{PENDAHULUAN}

Mesir merupakan salah satu Negara di kawasan Timur Tengah yang sangat kaya dan dikenal dengan khazanah keislamannya. Semenjak masuknya Islam ke Negara tersebut dan Amr bin 'Ash menjadi gubernur pertama di bawah ke-Khalifahan Umar Ibn alKhattab, di negeri ini telah bermunculan para pemikir muslim dan pembaharu yang sangat brilian.

Zaman keemasan Islam adalah zaman di mana banyak bermunculan para ilmuwan muslim, yaitu tepatnya pada masa Daulah Abbasiyah. Kita mengetahui bahwa salah seorang imam madzhab Islam terbesar, Muhammad bin Idris al-Syafi'i atau yang dikenal dengan Imam Syafi'i, hampir separuh usianya beliau habiskan di Mesir. Pada tataran militer, negeri ini pernah dijadikan markas besar oleh mujâhid besar, Shalahuddin al-Ayyubi yang membebaskan al-Quds dari tangan kaum Nashrani.

Pada abad ke-19, kita mendengar tokoh pembaharu seperti Jamaluddin al-Afghani (meskipun bukan kelahiran Mesir) (1838-1897 M), yang bersama-sama dengan Syaikh Muhammad Abduh (1849-1905 M) menerbitkan majalah al- 'Urwah al-Wutsqâ di Paris. Afghani adalah seorang pembaharu yang berusaha keras membela dunia Islam dan membebaskan mereka dari genggaman para penjajah dan terkenal dengan ide pan Islamismenya (al-Jâmi'ah al-Islâmiyah).

Adapun Muhammad Abduh adalah seorang ulama yang berusaha keras melakukan pembaharuan dan mendialogkan ajaran Islam (terutama syarî'ah) dengan realitas masyarakat yang dihadapinya. Begitu pula muridnya, Sayyid Muhammad Rasyid Ridha (1865-1935 M), yang meneruskan tafsir al-Manâr karya Muhammad Abduh dan menerbitkan majalah al-Manâr. Kemudian disusul ulama-ulama Al-Azhar lainnya yang tidak mungkin kami sebutkan satu persatu. Tentu saja rentang waktu antara Imam Syafi'i dengan Jamaluddin al-Afghani tersebut, di Mesir telah banyak pemikir besar lainnya yang muncul.

Pada wacana pemikiran kaum intelektual muslim Mesir ini, sekitar awal abad ke-14 Hijriyah atau abad ke-19 Masehi, terjadi polemik besar antara kaum pembaharu dan kaum tradisional. Di satu sisi, kaum pembaharu berusaha keras agar dapat menghadapkan dan membawa Islam kepada persoalan-persoalan kontemporer yang tidak pernah muncul pada zaman klasik, sedangkan di sisi lain kaum tradisionalis sama sekali menolak ide pembaharuan tersebut dan mereka menangkapnya dengan penuh kecurigaan bahkan mereka menganggap bahwa ide pembaharuan hanyalah merupakan sebuah ide besar berbau Barat yang akan menghancurkan prinsip-prinsip ajaran Islam, padahal bagi para pembaharu, upaya tajdid ini adalah sebuah keniscayaan (necessity), karena tanpanya, Islam tidak akan dapat menyentuh persoalan-persoalan baru. Akan tetapi, pembaharuan yang dilakukan harus tetap memperhatikan prinsip-prinsip pokok Islam yang tidak dapat berubah (tsawâbit). ${ }^{204}$

Tentu saja arah berlawanan ini menimbulkan polemik besar dan berkepanjangan. Akan tetapi, akhirnya polemik tersebut mulai menjinak dengan munculnya beberapa pemikir baru Mesir pada awal abad ke-20 yang di antaranya adalah Syaikh Muhammad al-Ghazali dan Dr. Yusuf Qardhawi. Syaikh Muhammad alGhazali adalah ulama yang merepresentasikan kaum pembaharu, sedangkan Syaikh Qardhawi adalah reprsentasi kaum tradisonal. Dengan hadirnya dua orang ulama ini, kubu pembaharu dan tradisional mulai saling berdialog dan mendekati, sehingga kemunculan dua orang tokoh tersebut (meminjam istilah Thariq al-Busyra) seperti dua buah lautan yang bertemu pada sebuah muara (multaqâ al-Bahrain), yaitu lautan para pembaharu dan lautan kaum tradisional, yang kemudian dua laut itu menjadi satu arus. Dengan demikian, dari kolaborasi 'cantik' antara dua pemikir ini, kita menemukan seorang pembaharu yang memiliki ruh tradisional dan pembela prinsipprinsip Islam (ushûl); dan seorang tradisionalis yang memiliki jiwa pembaharu yang menggunakan tajdid sebagai jalan untuk mempertahankan eksistensi dan 204 Muhammad Imarah, al-Madrasat al-Fikriyah: Madrasat al-Ihyâ
wa al-Fajâât. Đalami alt-Muslim al-Mu'âshir, edisi ke-100, tahun ke-25, h. 9. 
ushûl Islam. ${ }^{205}$ Dengan demikian, gaya pemikiran Islam seperti ini, akan dapat menjadikan Islam lebih dapat berdialog dan harmonis dengan zaman, tetapi ia tidak kehilangan kemurniannya.

Dua orang ulama ini adalah alumni Universitas Al-Azhar Mesir. Mereka sering sekali mendialogkan pemikirannya secara terbuka. Salah satunya adalah ketika Syaikh Muhammad al-Ghazali menulis sebuah buku yang berisi rekontruksi standar keshahihan hadits berdasarkan makna (matan) dan tidak hanya mendasarkannya kepada kredibilitas para perawi (sanad) seperti yang dilakuakn oleh para ulama klasik. Buku tersebut berjudul: al-Sunnat al-Nabawiyyat baina Ahl al-Fiqh wa Ahl al-Hadîts. Kemudian Syaikh Qardhawi berusaha mengkritik metodologi Syaikh al-Ghazali ini dengan metodolgi klasik yang sangat dikuasainya. Buku tersebut berjudul Kaifa nata'âmal ma'a al-Sunnat al-Nabawiyah (Bagaimanakah seharusnya memperlakukan Sunnah Nabawiyah). Kedua buku tersebut telah diterjemahkan ke dalam bahasa Indonesia. Kedua tokoh ini adalah dua orang ulama yang memiliki kedekatan secara personal dan pernah bersama-sama menjadi penghuni penjara Thûr, bahkan Qardhawi menulis buku yang secara khusus menceritakan kedekatannya dengan Syaikh Muhammad al-Ghazali yang berjudul: al-Syaikh alGhazâlî Kamâ Araftuhu: Rihlah Nishf Qarn. Saat ini, setelah Syaikh Muhammad al-Ghazali meninggal dunia (bulan Maret tahun 1996), ${ }^{206}$ Syaikh Qardhawi terus berjuang dan berkarya untuk kebangkitan umat.

Tentu saja untuk memaparkan perjalanan dan jasa mereka terhadap Islam. Kami hanya akan menulis sebagian kecil kontribusi yang telah diberikan Qardhawi, salah seorang ulama yang masih hidup dan berusaha keras meneruskan cita-cita para pendahulunya tersebut terhadap Islam.

\section{Perjalanan Hidup Syaikh Qardhawi}

Syaikh Yusuf Qardhawi yang semenjak duduk di tingkat keempat Ibtida'iyah selalu dijuluki 'Yâ Allâmah' atau syaikh oleh para gurunya, beliau dilahirkan di sebuah kampung kecil yang bernama Shaft Turab. Ia adalah salah satu perkampungan asri Mesir yang terdapat di Provinsi Gharbiyah, dengan ibu kotanya Thantha. Dari Kairo, kampung tesebut berjarak seki$\operatorname{tar} 150$ kilo meter atau untuk menempuhnya membu-

\footnotetext{
205 Thariq al-Busyra. Syakhshiyat wa Qadhaya Mu'asharah. (Al-Hilal: Kairo, 2002). 78 dan 80

206 Pada tahun ini, pada bulan yang sama di Mesir telah meningal tiga orang ulama bear yang menjadi simbol kebesaran umat Islam Msir, yaitu: Ustadz Khalid Muhammad Khalid, kemudian Syaikh Muhammad al-Ghazali, kemudian Syaikh Jad al-Haq Ali Jad al-Haq (mantan Syaikh al-Azhar), kemudian Dr. Ishmat Saif al-Daulah.
}

tuhkan waktu sekitar 3-4 jam. Tepatnya ia dilahirkan pada tanggal 09 September 1926 dari pasangan suami istri yang sangat sederhana tetapi taat beagama. Ia tidak berkesempatan mengenal ayah kandungnya dengan baik, karena tepat usianya baru mencapai dua tahun, ayah yang dicintainya telah meninggal dunia. ${ }^{207}$

Setelah ayah kandungnya meninggal dunia, ia diasuh dan dibesarkan oleh ibu kandung, kakek dan pamannya. Akan tetapi pada saat ia duduk di tahun keempat Ibtidaiyah Al-Azhar, ibunya pun dipanggil yang maha kuasa. Beruntung, ibu yang dicintainya masih sempat menyaksikan putra tunggalnya ini hafal seluruh al-Quran dengan bacaan yang sangat fasih, karena pada usia sembilan tahun sepuluh bulan, ia telah hafal al-Qu'ran di bawah bimbingan seorang kuttâb yang bernama Syaikh Hamid. ${ }^{208}$ Setelah ayah, Ibu dan kakeknya meninggal dunia, ia diasuh dan dibimbing oleh pamannya. Pendidikan formalnya dimulai pada salah satu lembaga pendidikan Al-Azhar yang dekat dengan kampungnya, yang hanya menerima calon siswanya yang sudah hafal al-Quran. Di lembaga pendidikan inilah Qardhawi kecil mulai bergelut dengan kedalaman khazanah Islam di bawah bimbingan para gurunya.

Pada masa kecilnya, di dalam jiwa Qardhawi terdapat dua orang ulama yang paling banyak memberikan warna dalam hidupnya, yaitu Syaikh AlBattah (salah seorang ulama alumni Al-Azhar di kampungnya) dan Ustadz Hasan al-Banna. Bagi Qardhawi, Syaikh al-Battah adalah orang yang pertama kali mengenalkannya kepada dunia fikih, terutama madzhab Maliki, sekaligus membawanya ke AlAzhar. Sedangkan Syaikh al-Banna adalah orang yang telah mengajarkannya cara hidup berjamaah, terutama dalam melaksanakan tugas-tugas berdakwah. Mengenai pengaruh al-Bana dalam dunia pemikiran dan spiritualnya, beliau pernah mengatakan: "Di antara orang-orang yang paling banyak memberikan pengaruh besar dalam dunia pemikiran dan spiritual kami adalah Syaikh al-Syâhid al-Banna." ${ }^{209}$

Setelah keluar dari madrasah tersebut, beliau melanjutkan ke Madrasah Ibtida-iyyah "Thantha", yang diselesaikannya dalam waktu empat tahun. Kemudian pindah ke Madrasah Tsanawiyyah yang

\footnotetext{
207 Sulaiman bin Shalih Al-Khurasyi, "Al-Qaradhaawiy Fỉl-Mizản”, diterjemahkan M. Abdul Ghoffar, Pemikiran Dr. Yusuf al-Qaradhawi Dalam Timbangan (Bogor: Pustaka Imam Asy-Syafi'i, 2003), h. 7.

208 Ishom Talimah, "al-Qardhawiy Faqiihaan", diterjemahkan Samson Rahman, Manhaj Fikih Yusuf al-Qaradhawi (Jakarta: Pustaka Al-Kautsar, 2001), h. 3.

209 http:/web -1skandar. Tripod.com, Diakses pada hari Kamis, 24 Januari 2011

(n) nitro $^{\text {PDF }^{\prime} \text { professional }}$
} 
samaselamalimatahun. ${ }^{210}$ Qardhawiterus melanjutkan ke Universitas al-Azhar, Fakultas Ushuluddin. Dan lulus tahun 1952. Tapi gelar doktornya baru ia peroleh pada tahun 1972 dengan disertasi "Zakat dan Dampaknya Dalam Penanggulangan Kemiskinan", yang kemudian disempurnakan menjadi Fiqh Zakat. Sebuah buku yang sangat komprehensif membahas persoalan zakat dengan nuansa modern. Dia terlambat memperoleh gelar doktornya karena situasi politik Mesir yang tidak menentu. ${ }^{211}$

Qardhawi memiliki tujuh anak. Empat putri dan tiga putra. Sebagai seorang ulama yang sangat terbuka, dia membebaskan anak-anaknya untuk menuntut ilmu apa saja sesuai dengan minat dan bakat serta kecenderungan masing-masing. Dan hebatnya lagi, dia tidak membedakan pendidikan yang harus ditempuh anak-anak perempuannya dan anak lakilakinya.

Salah seorang putrinya memperoleh gelar doktor fisika dalam bidang nuklir dari Inggris. Putri keduanya memperoleh gelar doktor dalam bidang kimia juga dari Inggris, sedangkan yang ketiga masih menempuh S3. Adapun yang keempat telah menyelesaikan pendidikan S1-nya di Universitas Texas Amerika. Anak laki-laki yang pertama menempuh S3 dalam bidang teknik elektro di Amerika, yang kedua belajar di Universitas Darul Ulum Mesir. Sedangkan yang bungsu telah menyelesaikan kuliahnya pada fakultas teknik jurusan listrik.

Dilihat dari beragamnya pendidikan anak-anaknya, orang-orang bisa membaca sikap dan pandangan Qardhawi terhadap pendidikan modern. Dari tujuh anaknya, hanya satu yang belajar di Universitas Darul Ulum Mesir dan menempuh pendidikan agama. Sedangkan yang lainnya, mengambil pendidikan umum dan semuanya ditempuh di luar negeri. Sebabnya ialah, karena Qardhawi merupakan seorang ulama yang menolak pembagian ilmu secara dikotomis. Semua ilmu bisa islami dan tidak islami, tergantung kepada orang yang memandang dan mempergunakannya. Pemisahan ilmu secara dikotomis itu, menurut Qardhawi, telah menghambat kemajuan umat Islam.

\section{Kontribusi Qardhawi bagi Islam}

Setidaknya Syaikh Qardhawi telah memberikan sumbangsih bagi agama Islam dalam dua hal, yaitu;

Pertama, Dalam Dunia Dakwah (Harakah Dan Shahwah Islamiyah), Shahwah adalah sebuah upaya

210 Sulaiman bin Shalih Al-Khurasyi, Op Cit., h. 8.

211 Ishom Talimah, "al-Qardhawiy Faqiihaan", diterjemahkan Samson Rahman, Manhaj Fikih Yusuf al-Qaradhawi (Jakarta: Pustaka Al-Kautsar, 2001), h. 4 . untuk membangkitkan umat dari keterlenaan, keterbelakangan, kejumudan dan melepaskan mereka dari konflik internal melalui berbagai wujud usaha dengan tujuan memperbaharui agama, sehingga dapat memperbaharui kehidupan dunia mereka. ${ }^{212}$

Pada tataran teknis, cita-cita shahwah tersebut berusaha diwujudkan dalam sebuah aktivitas hara$k a h$. Ia menyadari bahwa untuk mencapai tujuan tersebut, tidak dapat dilakukan secara individual, tetapi ia membutuhkan sebuah kerja massal ('amal jamâ'i) yang tersusun dan terprogram secara rapi. Oleh karena hal inilah maka semenjak duduk di tingkat Tsanawiyah, Qardhawi telah memulai tugas berdakwah dengan bergabung bersama Ikhwan dan semenjak awal, ia telah dipersiapkan agar menjadi salah seorang kader terbaik mereka. Salah satunya adalah pada saat ia ditunjuk untuk menjadi da'i Ikhwan untuk seluruh Mesir, dari Provinsi Alexandria (Iskandariyah) sampai Aswan dan Sinai, bahkan ia pernah ditugaskan berdakwah di beberapa negara Arab seperti Suria, Libanon dan Yordania, dengan dana yang didapatkannya dari Ustadz Hasan al-Hudhaibi, Mursyid 'âm Ikhwan yang kedua, padahal saat itu ia masih berstatus sebagai seorang mahasiswa. ${ }^{213}$

Selain menjadi aktivis di lapangan, Qardhawi juga merupakan salah seorang pemikir yang ideidenya banyak dijadikan sebagai referensi oleh para aktivis harakah. Menurutnya, yang dimaksud dengan harakah adalah sebuah pekerjaan yang dilakukan secara kolektif dan dimulai dari masyarakat paling bawah (bottom up) dan terorganisir secara rapih dalam upaya mengembalikan masyarakat kepada ajaran Islam. ${ }^{214}$ Menurut Qardhawi, tujuan utama yang harus direalisasikan oleh sebuah harakah Islamiyah adalah bagaimana mewujudkan sebuah pembaharuan (tajdîd). Melakukan tajdîd adalah merupakan sebuah sunnatullah yang akan terus berulang. Hal ini ditegaskan dalam sebuah hadis riwayat Abu Dawud dan al-Hakim: "Sesunggunya pada setiap seratus tahun, Allah akan mengutus untuk umat ini, orang yang memperbaharui agamanya". Yang dimaksudkannya dengan pembaharuan (tajdid) adalah sebuah upaya untuk memperbaharui pemahaman keagamaan, keimanan, sikap iltizam kepada agama serta memperbaharui metode dakwah yang digunakan. Ia bukanlah sebuah usaha untuk membuat aturan baru dalam agama dengan merubah prinsip-prinsip baku

\footnotetext{
212 Muhammad Imarah. Al-Shahwah. Dalam al-Mausu'ah al-Islamiyah al- 'Amah. (Kairo: Wazarah al-Auqaf, 2001) h. 850.

213 Ishom Talimah, Op.Cit, 23-24.

214 Cryusuf Qardhawi, Al-Ikhwan Al-Muslimun Sab'una 'Aman $f i$ alDa'wah wa al-Tarbiyah wa al-Jihad. Maktabah Wahbah: Kairo 1999. 31.
} 
(tsawabit) atau merusak tatanan ajaran yang qath ' $\boldsymbol{i}_{\mathbf{.}}$

Kedua, Pemikiran Yusuf Qardhawi Dalam Bidang Fikih, Seorang fakih yang benar-benar fakih adalah orang yang mengetahui secara lengkap tentang al-Qur'an dan Ulum al-Qur'an, Sunnah dan Ilmu Hadits serta ilmu-ilmu yang berhubungan dengan keduanya seperti, bahasa Arab dan sastranya, fikih perbandingan dan masalah-masalah khilafiyah. Selain itu ia dituntut untuk menguasai ilmu ushul fikih, maksud-maksud syari'ah dan benar-benar menguasai masalah-masalah fikih. Dia juga dituntut untuk mengerti banyak tentang realitas kehidupan saat ini. Sebagai seorang fakih maka syarat-syarat tersebut telah dimiliki oleh Yusuf Qardhawi.

Salah satu faktor yang mempengaruhi pemikiran Yusuf Qardhawi adalah peristiwa istimewa yang dialaminya di tingkat Ibtida'iyah yaitu pada saat pertama kali ia mendengarkan ceramah ustad al-Banna. Ketika mendengarkan ceramahnya, intuisi Qardhawi kecil mulai dapat merasakan kehadiran seorang lakilaki alim yang telah menggadaikan seluruh hidupnya hanya untuk kepentingan Islam dan umatnya. Karena kesadaran dan pemahaman akan pentingnya dakwah yang dilakukan secara berjamaah, maka ia mulai bergabung bersama Ikhwanul Muslimin. ${ }^{215}$ Kelompok ini mempunyai kelebihan yang tidak dimiliki oleh kelompok lainnya, yaitu fanatisme berlebihan terhadap pendirinya, Hasan al-Banna. ${ }^{216}$

Al-Qardhawi terkenal sebagai salah seorang yang sangat berpegang teguh pada sikap moderasi, baik dalam bidang pemikiran, fikih, ataupun dakwah. Pengakuan ini bukan saja datang dari kalangan Islamis, namun juga dari orang-orang non-muslim. Diantaranya yaitu Syeikh Muhammad al-Ghazali, Dr. Muhammad Imarah dan lain-lain.

Sikap moderat yang diambil Yusuf Qardhawi bersumber dari al-Qur'an dan Sunnah. Karena Islam sendiri adalah agama moderat, dan karakter umat Islam adalah umat moderat. Hal ini sesuai dengan apa yang tercantum dalam beberapa ayat diantaranya surat al-Baqarah: 143, ar-Rahman: 7-9, dan al-A'raaf: 31 dimana ayat-ayat tersebut memerintahkan kita agar bersikap moderat. Selain dari beberapa ayat di atas pada kehidupan Rasulullah juga dipenuhi dengan sikap dan seruan kepada sikap moderat. ${ }^{217}$

Selain sebagai ulama yang terkenal sangat memegang teguh sikap moderasi, Yusuf Qardhawi memilih metode fikihnya dengan semangat toleransi

215 http://web -iskandar. Tripod.com, Diakses pada hari Kamis, 24 Juni 2010. 216 Sulaiman bin Shalih Al-Khurasyi, Op Cit., 13.

217 Ishom Talimah, Op Cit., 57-66. (tasâmuh), lintas madzhab dan selalu menghendaki kemudahan bagi umat (taisîr), serta mengakses penggalian hukum secara langsung dari sumbernya yang asli, yaitu al-Quran dan sunnah shahihah. Dengan metode inilah Qardhawi menjelajahi dunia fikih, dari tema-tema yang paling kecil seperti masalah lalat yang hingap pada air, sampai masalah yang paling besar seperti 'Bagaimanakah Islam menata sebuah negara'?, atau dari tema yang paling klasik seperti masalah thahârah, sampai yang paling kontemporer seperti masalah demokrasi, HAM, peranan wanita dalam masyarakat dan pluralisme (ta'addudiyah).

\section{Kesimpulan}

Yusuf Qardawi dilahirkan pada tanggal 09 September 1926, nama beliau mulai muncul pada awal abad ke-20 saat beliua menjinakkan polemik antara kaum pembaharu dan tradisional, yang muncul sekitar awal abad ke 14 hingga abad ke 19. Tidak hanya itu, nama Yusuf Qardhawi semakin besar karna beliau telah banyak memberikan sumbangsih bagi agama Islam dalam dua hal, yaitu; Pertama, Dalam Dunia Dakwah (Harakah Dan Shahwah Islamiyah), dan Kedua, Pemikiran Yusuf Qardhawi Dalam Bidang Fikih, beliau juga berpegang teguh pada sikap moderasi.

\section{DAFTAR PUSTAKA}

Al-Jauziyah, Ibn Qayyim. 'Ilâm al-Muwâqi'în. (Dar al-Fikr: Beirut). 1976.

Busyra, Thariq. Syakhshiyatwa QadhayaMu'asharah. (Al-Hilal: Kairo). 2002.

Farhat, Muhamad Nur. al-Bahtsu 'an al-'Aql: Hiwâr ma'a fikr al-Hâkimiyah wa al-Naql. (Dar alHilâl: Kairo).1997.

Imarah, Muhammad. al-Madrasah al-Fikriyah: Madrasat al-Ihyâ wa al-Tajdîd. Dalam alMuslim al-Mu'âshir, edisi ke-100, tahu ke-25 (Muharram-Rabi'ul Awwal $1422 \mathrm{H}$ ).

--------, Al-Shahwah. Dalam al-Mausu'ah alIslamiyah al- 'Amah. Wazarah al-Auqaf:: Kairo. 2001.

Qardhawi, Yusuf. al-Shahwat al-Islâmiyyah baina alJuhûd wa al-Tatharruf. Bank al-Taqwa. (tanpa kota). $1402 \mathrm{H}$.

---------, pada jurnal al-Muslim al-Mu'ashir yang berjudul: al-Fiqh al-Islami bain al-Ashalah wa al-Tajdid. Edisi 3 (rajab 1395/Juli 1975.

---, Min Fiqhal-Daulatfíal-Islâm: Makânatuhâ, Ma'âlimuhâ, Thabî'atuhâ, Mauqifuhâ Min alDimuqrâthiyah, wa al-Ta'addudiyyah wa alMargahtahat Ghair al-Muslimîn. Dâr al-Syurûq: (n) ${ }^{2000}$ nitro $^{\text {PDF }}$ professional 
Marhalat al-Qadimah. Mu'assasah Risalah:

Beirut. 1997.

, Al-Siyasah al-Syar'iyyah fidhau'i nushuh alSyari'ah wa maqashidiha. Maktabah Wahbah, Kairo. 1998. Halaman 228. Mu'assasah Risalah: Beirut. 1997.

--, Min ajli Shahwah Rasyîdah. Dâr al-Syurûq: Kairo. 2001.

, Syari'at al-Islam. A-Maktabah al-Islamiyah Beirut (tanpa tahun).

---------, AL-Ikhwan AL-Muslimun Sab'una 'Aman fi al-Da'wah wa al-Tarbiyat wa al-Jihad. Maktabah Wahbah: Kairo 1999.

-, Ummatuna baina Qarnai. Dâr al-Syurûq: Kairo. 2000.

Talimah, Isham. Al-Qardhawi Faqîhan. Dâr al-Tauzî Wa al-Nsyr al-Islâmiyah: Kairo. 2000. 